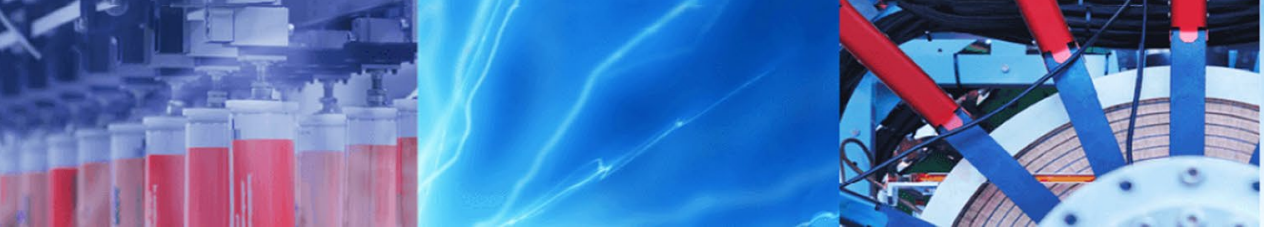

Research Article

\title{
Microstructural studies of direct-laser-deposited stainless steel 316L-Si on 316L base material
}

\author{
Marius Aga Belsvik $^{1}$ (D) Wakshum M. Tucho ${ }^{1} \cdot$ Vidar Hansen $^{1}$
}

Received: 14 May 2020 / Accepted: 16 September 2020 / Published online: 9 November 2020

(c) Springer Nature Switzerland AG 2020

\begin{abstract}
Microstructure and hardness of SS316L-Si deposited by direct laser deposition (DLD) on a conventional SS316L base material are studied. The DLD process produced a crack-free metallic part with a density of $\sim 99.5 \%$. The as-deposited samples exhibit a microstructure with millimetre-sized solidified melt pools. They consist mainly of columnar dendrites which were formed preferentially along $<001>$ direction, generating solidification texture and columnar grains. Dendrites with cellular morphology were also formed in regions of higher solidification rates, mainly above the localized heat-affected zone in the layers. The deposited SS316L-Si contains a primary austenitic matrix and secondary $\delta$-ferrite in the interdendritic regions. The average hardness measured along parallel and normal surfaces with respect to the building direction is nearly the same $(\sim 185 \mathrm{HV})$, indicating homogeneity in the microstructure of the as-deposited SS316L-Si along the two orthogonal surfaces. The analysis of microstructure, defects and intermetallic phases was carried out using optical microscopy, scanning electron microscopy and transmission electron microscopy.
\end{abstract}

Keywords Additive manufacturing $\cdot 316 \mathrm{~L}-$ Si stainless steel $\cdot$ Microstructure $\cdot$ Secondary phase $\cdot$ Porosity $\cdot$ Hardness

\section{Introduction}

Additive manufacturing (AM), or 3-D printing, has shown a remarkable development, starting from poor prototyping [1], to production of fully functional parts for various applications, including medical, aerospace, automotive, oil, gas, and space industries [2-6]. Today, there exist several varieties of AM techniques for producing near-net shape parts by deposition of material using a laser beam. Some of these methods are laser engineered net shaping (LENS) [2], laser metal deposition shaping (LMDS) [3], laser solid forming (LSF) [4] and direct laser deposition (DLD) [5]. DLD is in the category of direct energy deposition (DED) that utilizes a concentrated heat source such as laser or electron beam. The feedstock delivered to the DLD machine can be in the form of powder or wire that melts by an applied laser/ electron beam to achieve layer-by-layer fabrication or repair of components. By applying highly developed laser and machine technology, DLD can customize and repair pre-existing parts, generate components with geometry beyond the capability of conventional manufacturing techniques and reduce material wastage significantly by directly depositing the material with fine precision, which reduce the need for costly equipment and machining [6]. DLD can also allow the design of components with specifically refined microstructures to achieve some desired properties, which is not possible with conventional manufacturing approaches [7]. Furthermore, the use of DLD is beneficial in terms of cost compared with some of the other AM methods.

Due to their wider range of applications, various types of AM-fabricated stainless steel have been studied for optimizing the microstructure and mechanical properties of the products. High-alloyed stainless steels such as

$\triangle$ Marius Aga Belsvik, marius.aga.belsvik@kvernelandgroup.com | ${ }^{1}$ Department of Mechanical and Structural Engineering and Materials Science, University of Stavanger, N-4036 Stavanger, Norway. 
SS316L, with larger amounts of chromium, molybdenum and nickel, are one of the most studied in the series since it is characterized with high corrosion resistance, good ductility, high strength and good weldability at relatively low cost. Consequently, the material is highly used in automotive, oil, gas and refinery, chemical plants, biomedical, constructions and nuclear reactors [8]. However, the microstructure, mechanical properties and phases present in the AM-fabricated SS316L are known to be different from that produced by conventional techniques.

The studies on SS316L fabricated by different AM techniques have been previously reported by several researchers. Saeidi et al. [9], for instance, studied the SLMfabricated SS316L, and reported a single-phase austenitic structure with molybdenum enrichment along the sub-grain boundaries and high density of dislocation concentrations. The study of the DLD-fabricated SS316L by Yadollahi et al. [7] showed the effects due to the process time interval. According to Yadollahi and co-workers, longer local time intervals led to higher cooling rates and finer microstructure. They have also observed pores and weaker metallurgical bonds as predominant defects in the last deposited layers due to reduced laser penetration. On the other hand, the relatively high cooling rates led to an adverse effect on layer adhesion and induced inter-track porosity [10]. Tucho et al. [11] studied the effects of process parameters on the hardness, porosity and microstructure of SLM-printed SS316L. Their conclusion indicates energy density as the most influential parameter for optimizing the fabrication of the SS316L with SLM technique. Based on the differences in technologies sought between DLD and powder-based methods (e.g. SLM), it is worthy to investigate the microstructure and mechanical properties of the DLD-fabricated parts. This would help to improve the technology for production of crucial structural parts of any geometrical complexity by avoiding post-processing such as machining and welding. The objective of the current work is thus to study the microstructure evolution of the SS316L-Si parts deposited on SS316L base material using DLD method. In particular, the study investigates variations in microstructure, solidification textures, phases, defects and hardness tests.

\section{Material and experimental methods}

The SS316L-Si parts studied were fabricated by direct laser deposition method using a TruLaser Cell 3000. The machine was equipped with a TruDisk 3001 laser of $3 \mathrm{~kW}$ solid-state Nd:YAG (neodymium-doped yttrium aluminium garnet) diodes. The DLD technique is schematically illustrated in Fig. 1a. The fabrication was carried out in an argon atmosphere to prevent the melt pool from oxidation. Helium was used as carrier gas for the powder material. The applied process parameters are given in Table 1.

The feedstock used was a gas-atomized MetcoClad SS316L-Si nickel-chromium stainless steel powder that is generally prepared for use by a laser cladding technique. The chemical composition of the powder is given in Table 2. The nominal size range of the powder is 44-106 $\mu \mathrm{m}$. Silicon content in the powder material is higher than in the regular SS316L. It was implemented to
Fig. 1 Direct laser deposition. a Schematic of the deposition process, b laser scanning tracks in different planes. The numbers $(1,3,2)$ indicate the deposition sequence of the material for the layers $\mathrm{N} 1$ to N15. c) SS316L base material and the deposited wings of SS316L-Si

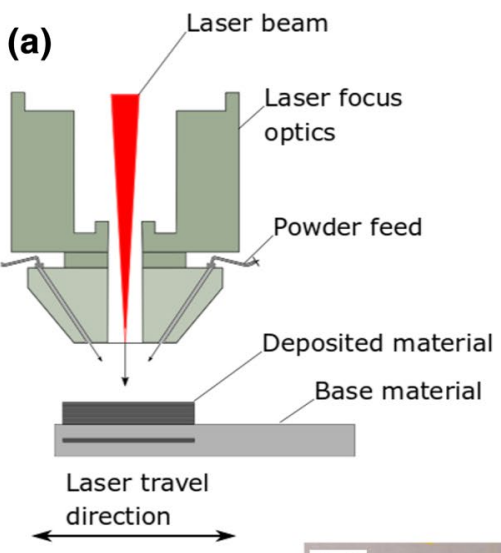

(b)
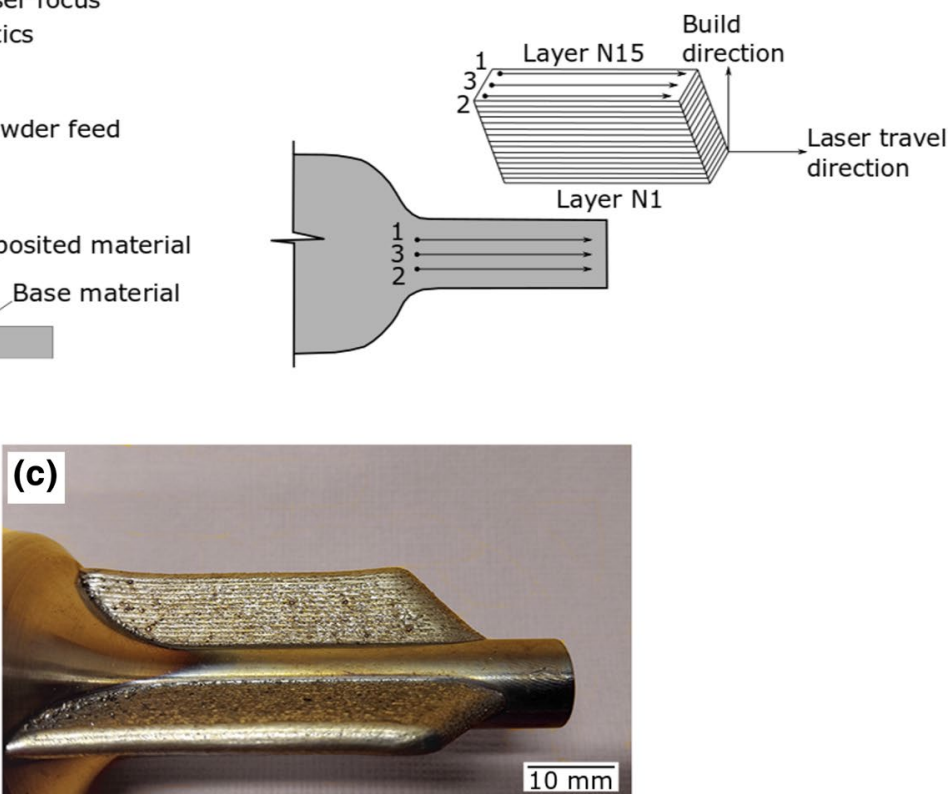
Table 1 The DLD-based process parameters for fabricating of SS316L-Si parts

\begin{tabular}{llllll}
\hline $\begin{array}{l}\text { Laser } \\
\text { power } \\
{[W]}\end{array}$ & $\begin{array}{l}\text { Laser } \\
\text { feed rate } \\
{\left[\mathrm{mm} \mathrm{s}^{-2}\right]}\end{array}$ & $\begin{array}{l}\text { Spot } \\
\text { diameter } \\
{[\mathrm{mm}]}\end{array}$ & $\begin{array}{l}\text { Powder } \\
\text { feed rate } \\
{\left[\mathrm{g} \mathrm{s}^{-1}\right]}\end{array}$ & $\begin{array}{l}\text { Layer } \\
\text { thickness } \\
{[\mathrm{mm}]}\end{array}$ & $\begin{array}{l}\text { Hatch } \\
\text { spacing } \\
{[\mathrm{mm}]}\end{array}$ \\
\hline 840 & 12 & 2.5 & 0.1 & 0.52 & 1.3 \\
\hline
\end{tabular}

act as a fluxing agent during the multi-pass deposition to improve wetting and facilitate a cleaner material deliverance [12].

The scanning sequences of the tracks are shown in Fig. 1b. The labels indicate deposition sequence, such that the middle track was scanned last. The deposited parts/ wings consist of 15 layers along the building direction. The SS316L-Si part was deposited on a 70-mm-long conventionally produced $316 \mathrm{~L}$ stainless steel rod with an outer diameter of $10 \mathrm{~mm}$. Three wings were deposited along the axis of the rod with a separation of about $120^{\circ}$ from each other as shown in Fig. 1c. The length, height and width of each of these wings are about 50, 10 and $4 \mathrm{~mm}$, respectively. During deposition, the laser scans across the length of the wings (parallel to the axis of the rod). The width of the wings is limited to 3 tracks, which is about $4 \mathrm{~mm}$ at the bottom.

The specimens studied were prepared from two orthogonal surfaces relative to the building direction. The specimen corresponding to the cross-sectional view (normal to the laser scanning plane or building direction) is referred to as sample CS, whereas the specimen with its surface parallel to the building direction is referred to as sample PS.

The microstructures of the specimens were studied with light optical microscopy (LOM, Olympus GX53), scanning electron microscopy (SEM, Gemini SUPRA 35VP equipped with EDAX energy-dispersive $X$-ray spectroscopy (EDS) detector) and transmission electron microscopy (TEM, JEOL-2100 with $\mathrm{LaB}_{6}$ filament, operating at 200 kV, equipped with EDS, bright-field and dark-field detectors). The crystallographic orientation and phases were studied using electron back-scattered diffraction (EBSD) detector equipped on SEM using TSL orientation imaging microscopy system. For microstructural observations with LOM and SEM, the specimens were ground and polished according to ASTM E03-11(2017) preparation guidelines for metallographic specimens [13]. After polishing, the samples were etched in a $10 \%$ aqueous oxalic acid by applying $15 \mathrm{~V}$ for $24 \mathrm{~s}$ for LOM observations. For
SEM analysis, the specimens were not chemically etched, but ultra-polished using $0.04-\mu \mathrm{m}$ colloidal silica (OP-S). For the TEM analysis, thin foils were prepared, first by thinning down mechanically to a thickness of about $100 \mu \mathrm{m}$, and then 3-mm discs were punched from the foils. These discs were then electropolished using a dual jet polishing system (Struers TENUPOL-5) at $-40{ }^{\circ} \mathrm{C}$ and $15 \mathrm{~V}$ in an electrolyte solution of $95 \%$ methanol and $5 \%$ perchloric acid.

To estimate the amounts of pores, SEM images were recorded from at least $50 \%$ of the total surface area from the cross-sectional view of the wings. The images were processed using ImageJ (license-free software) to quantify the porosity level. Hardness measurements were taken using a Vickers Struers DuraScan hardness tester under $5 \mathrm{~kg} \mathrm{HV}$ force for a dwell time of $10 \mathrm{~s}$ during indentations. Surfaces of the specimens were polished according to the requirements for Vickers hardness testing. The hardness measurements were taken on two sets (normal- and parallel to the build direction) of specimens to assess anisotropic properties of the material. The interval between successive indentations was $1 \mathrm{~mm}$. Similarly, the closest indentation near the base material is about $3 \mathrm{~mm}$. The mean hardness values were obtained by averaging a minimum of 8 measurements for each specimen tested.

\section{Experimental results and discussions}

\subsection{Microstructure}

The overview of the microstructure of sample CS (crosssectional view) and sample PS (plane view) is displayed in Fig. 2a, b), respectively. As the images reveal, the main building components of the microstructure of the DLDdeposited part are arc-shaped, solidified melt pools. This is consistent with previous reports on AM-fabricated metals revealing a common feature with other $A M$ techniques. The size of the DLD-fabricated melt pools is in the order of millimetres, which is by far larger than that of the powderbed techniques such as SLM (about $100 \mu \mathrm{m}$ ). The transverse (width) of the deposited wings at the base is about $4 \mathrm{~mm}$, each. As shown in Fig. 2a, the base of the wing adjacent to the base material consists of three melt pools. The width of the wing at the top, however, accommodates only one melt pool to meet the designed shape. The height of each of the wings is equivalent to 15 layers. The average thickness of the layers is about $1 \mathrm{~mm}$. Measurements show that each of the overlaying layers penetrates the
Table 2 Chemical composition (in wt. \%) of MetcoClad SS316L-Si powder

\begin{tabular}{llllllll}
\hline $\mathrm{C}$ & $\mathrm{Mn}$ & $\mathrm{Si}$ & $\mathrm{Cr}$ & $\mathrm{Ni}$ & $\mathrm{Mo}$ & Other & $\mathrm{Fe}$ \\
\hline 0.03 & 1.0 & 2.3 & 17.0 & 12.0 & 2.5 & $\leq 0.5$ & Balance \\
\hline
\end{tabular}



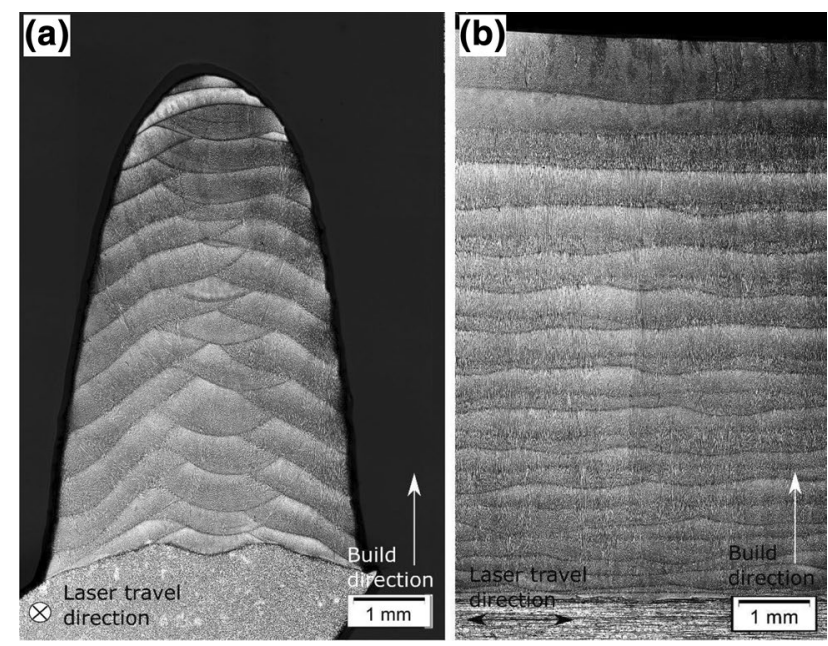

Fig. 2 LOM images showing the microstructure of etched sample surfaces revealing melt pools and fusion lines- $\mathbf{a}$ sample CS and $\mathbf{b}$ sample PS

preceding layer by about $150-250 \mu \mathrm{m}$. The overlapped nature of the layers ensures a strong fusion between them and consequently produces a dense structure.

Figure 3 shows the local variations in the microstructure as recorded with LOM. The heat-affected zones shown in Fig. $3 \mathrm{a}$ are approximately $100 \mu \mathrm{m}$ wide and characterized with a coarser structure compared to the adjacent regions. As the layer is deposited, the previous layer still maintains a high temperature (due to repeated remelting), which prevents the melt pool from cooling quickly. This favours the formation of a band containing cellular and some planar dendrites between the layers. Some of the dendritic structures are grown further beyond the zone, being influenced by the thermal gradient. The occurrences of these features in the microstructure are mainly due to the high temperature gradient and cooling rates associated with the rapid solidification process of DLD.

The cooling rate experienced by the material can be calculated by measuring the secondary dendrite arm spacing (SDAS). The image shown in Fig. 3b exhibits some of the evenly distributed dendrites with secondary arms. The average SDAS $\left(\lambda_{2}\right)$ measured is about $2.39 \mu \mathrm{m}$. The cooling rate, $\dot{T}$, can then be calculated using the well-established formulation given by Eq. (1) [14] as implemented on several types of austenitic stainless steel [15].

$\lambda_{2}=25 \dot{T}^{-0.28}$

Using Eq. (1), the average cooling rate obtained is approximately $4400 \mathrm{Ks}^{-1}$, which is consistent with the values reported in the literature [16]. The individual measurements of the SDAS, however, show variations in the cooling rate between the deposited layers. Areas in close proximity to the surrounding material, just above the local heat-affected zone between two layers, experience the highest cooling rate that gradually reduces towards the middle of the melt pool and upwards. The temperature gradient between the melt pool and the pre-deposited material is normally highest perpendicular to the previously deposited layer, resulting in thermally guided growth of the dendrites.

The microstructural morphology of the deposited SS316L-Si can be estimated based on the ratio $\mathrm{GV}^{-1}$, where $G$ and $V$ are temperature gradient and solidification velocity, respectively. The model proposed by Rosa and co-workers [17] illustrated in Fig. 4 also give comparable results with the predictions obtained based on the ratio of $\mathrm{GV}^{-1}$.

As the solid-liquid interface and heat accumulation migrate, the temperature gradient decreases in the
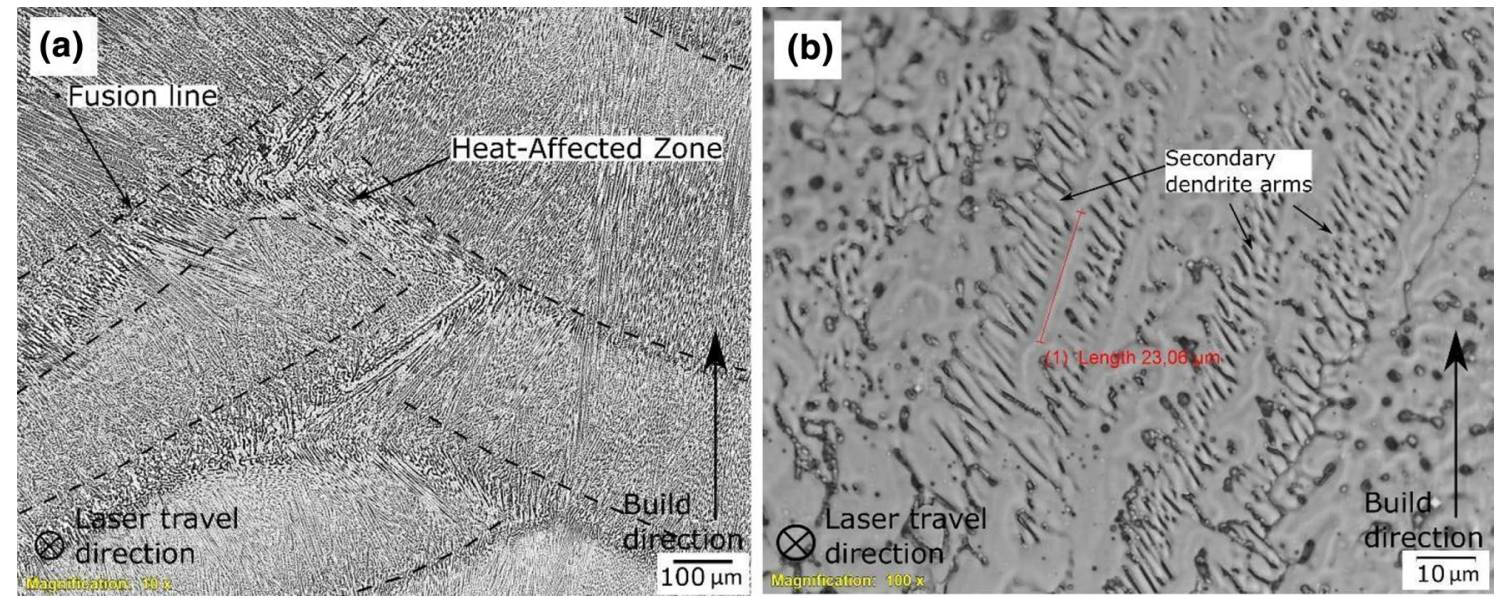

Fig. 3 LOM images of sample CS. a Fusion lines and local heat-affected zones between adjacent layers. b Dendritic structure of the deposited SS316L-Si secondary arms

\section{SN Applied Sciences}




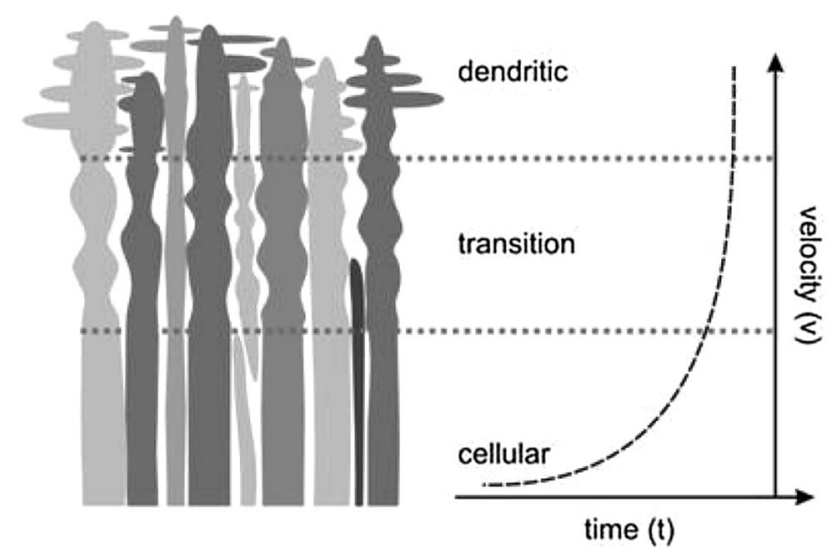

Fig. 4 Illustration of the dendrite structures development showing solidification velocity over time [17]. The figure is reproduced after permission from the authors

deposited layer. As the solidification velocity increases, it favours the growth of columnar dendrites along the temperature gradient. The perturbations that occur along the sides of the columnar dendrites may eventually evolve into secondary dendritic arms. Towards the centre of the melt pool, the temperature gradient is low which results in a low solidification velocity. This condition favours the growth of a cellular dendritic structure [18]. Further analysis shows that when $\mathrm{GV}^{-1}$ exceeds a critical value of 0.5 for SS316L, the grains formed are mainly equiaxed [19]. Figure $5 a, b$ shows how the secondary arms tend to fuse together to form columnar grains. Furthermore, the columnar grains continued growing epitaxially since parts of the grains subjected to repeated remelting prevent nucleation of new grains. Like welding techniques, the formation of large columnar grains tends to influence the yield and the tensile strength of the material. Addition of inoculants to the powder material could facilitate heterogeneous nucleation of equiaxed grains in front of the growing dendritic interface and thus refine the columnar grain structure [20].

Due to comparatively (to welding) low heat input and rapid cooling, the base material does not experience temperatures that lead to the formation of a large heataffected zone. This condition, however, results in the formation of a $200-\mu \mathrm{m}$ wide band with coarser grains in the base material as shown in Fig. 6a. Adjacent to the band of coarser grains, we have observed a narrow band with slightly finer grains that gradually blend into the unaffected base material. The figure also shows a solid metallurgical fusion between the base and the deposited materials. An EBSD inverse pole figure map of the fusion zone is given in Fig. 6b. It shows a band of refined grains along the fusion zone and slightly coarsened grains in the HAZ.

Figure 7 shows the EBSD crystal orientation map of sample PS, exhibiting the fusion boundary between the base and the first layer of deposited material, N1. The corresponding inverse pole figure orientation map is shown in Fig. 7a. The epitaxial nucleation of the grains of the deposited material on the base material is clearly seen. The fusion zone adjacent to $\mathrm{N} 2$ also reveals some equiaxial grains in the local heat-affected zone between the layers as shown in Fig. $7 \mathrm{~b}$.

Close investigation shows that the microstructure near the edge and centre region varies for some of the layers. However, the first deposited layer N1 exhibits similar microstructure in these two regions, suggesting an even solidification process. Due to the low initial temperature (room temperature) of the base material, the first layer experienced a high solidification rate and heat flux propagating mainly perpendicular to the base material surface. This condition facilitates the growth of elongated
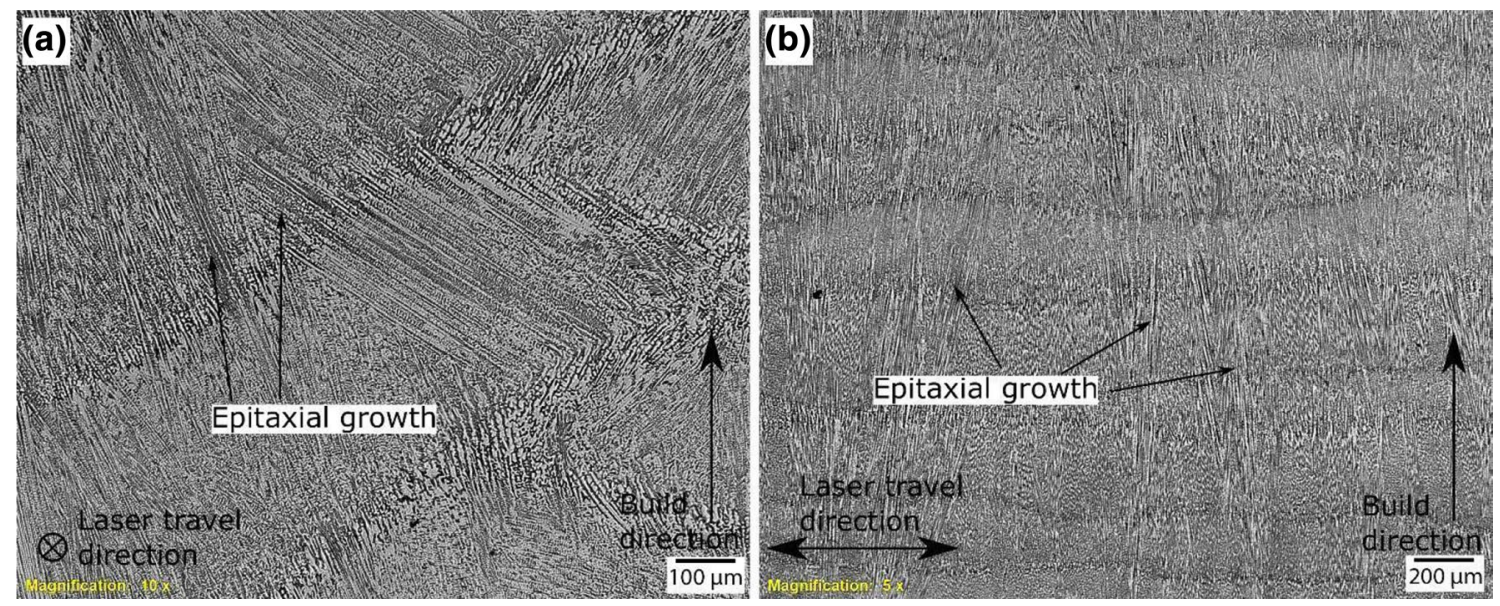

Fig. 5 LOM images showing directional growth of the dendrites. Epitaxial growth of the grains across a fusion zone (sample CS) and $\mathbf{b}$ several layers (sample PS) 

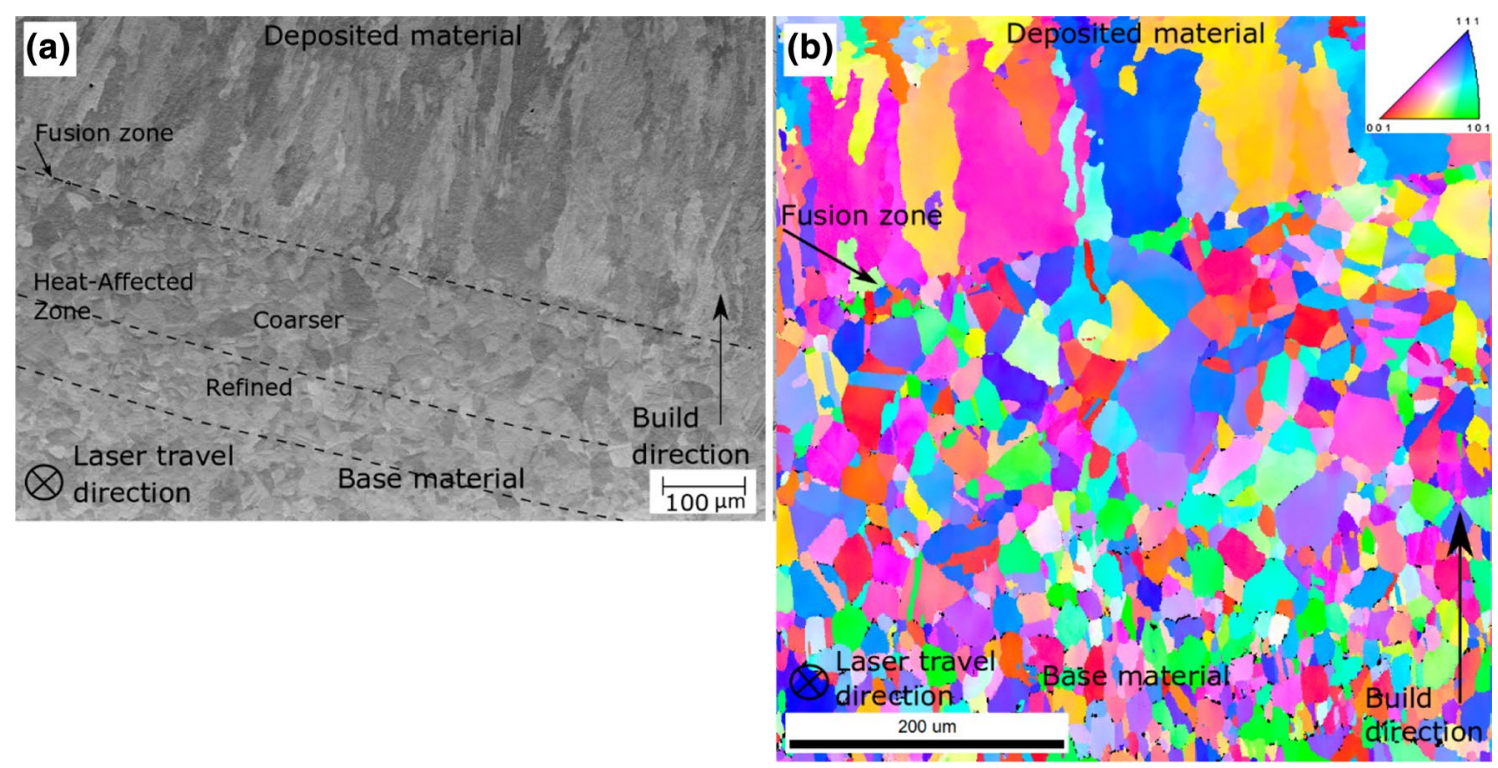

Fig. 6 Heat-affected zone of base material (sample CS). a SEM

trating grain structures on either side of the boundary between the image showing the 200- $\mu \mathrm{m}$ and $50-\mu \mathrm{m}$ bands of coarser and finer austenitic grains, respectively. b An EBSD inverse pole figure illus-

Fig. 7 EBSD map of the HAZ in sample PS. a Inverse pole figure and $\mathbf{b}$ image quality map. The upper and the lower dashed lines are approximate borders between base material and deposited layers and between $\mathrm{N} 1$ and $\mathrm{N} 2$, respectively
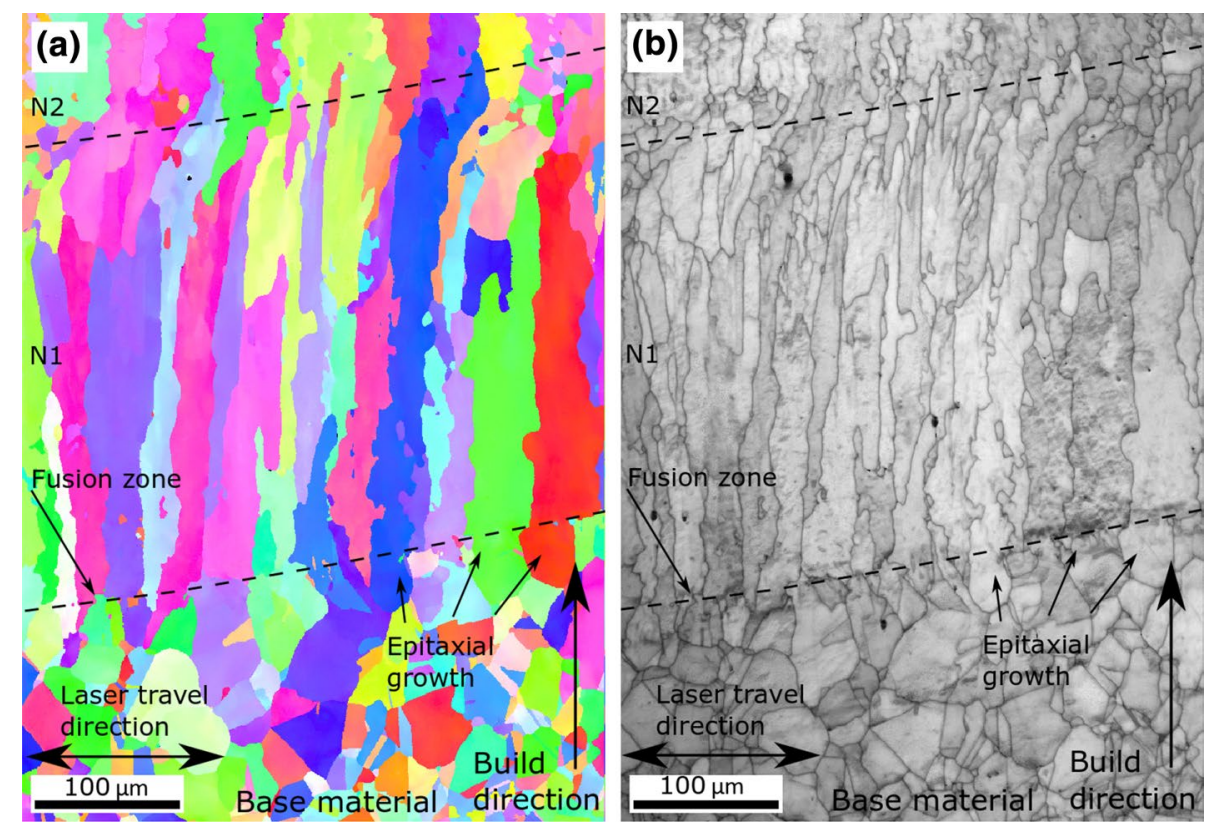

and columnar dendrites. The layers towards the middle, along the height of the deposited wings (N7, for example), exhibit some variations in the microstructure between the two regions. These layers were deposited when the bulk temperature had increased significantly as compared to $\mathrm{N} 1$, resulting in a relatively slower solidification rate. Since the centre line was deposited last, it was surrounded by excessive heat that promoted the formation of clusters of cellular and columnar dendrites. The cellular dendrites appear without secondary arms as shown in Fig. 8. Accordingly, cellular dendrites dominate the centre region (Fig. 8a, b), while the edge region is seen with more of the columnar dendrites (Fig. 8c, d). Comparatively, the microstructure of $\mathrm{N} 11$ (a layer closer to the tip of the wing) appears similar to that of N7. Columnar structure is thus more dominant towards the edge than around the centre of the layer. N15 is the last deposited layer at the top of the wings. It consisted of homogeneous clusters of 
Fig. 8 LOM image showing the microstructure of layer N7 of sample CS. a Cellular dendrites observed around the centre, b high-magnification image of (a), c columnar dendrites with secondary dendritic arms observed towards the edge and $\mathbf{d}$ high-magnification image of (c)
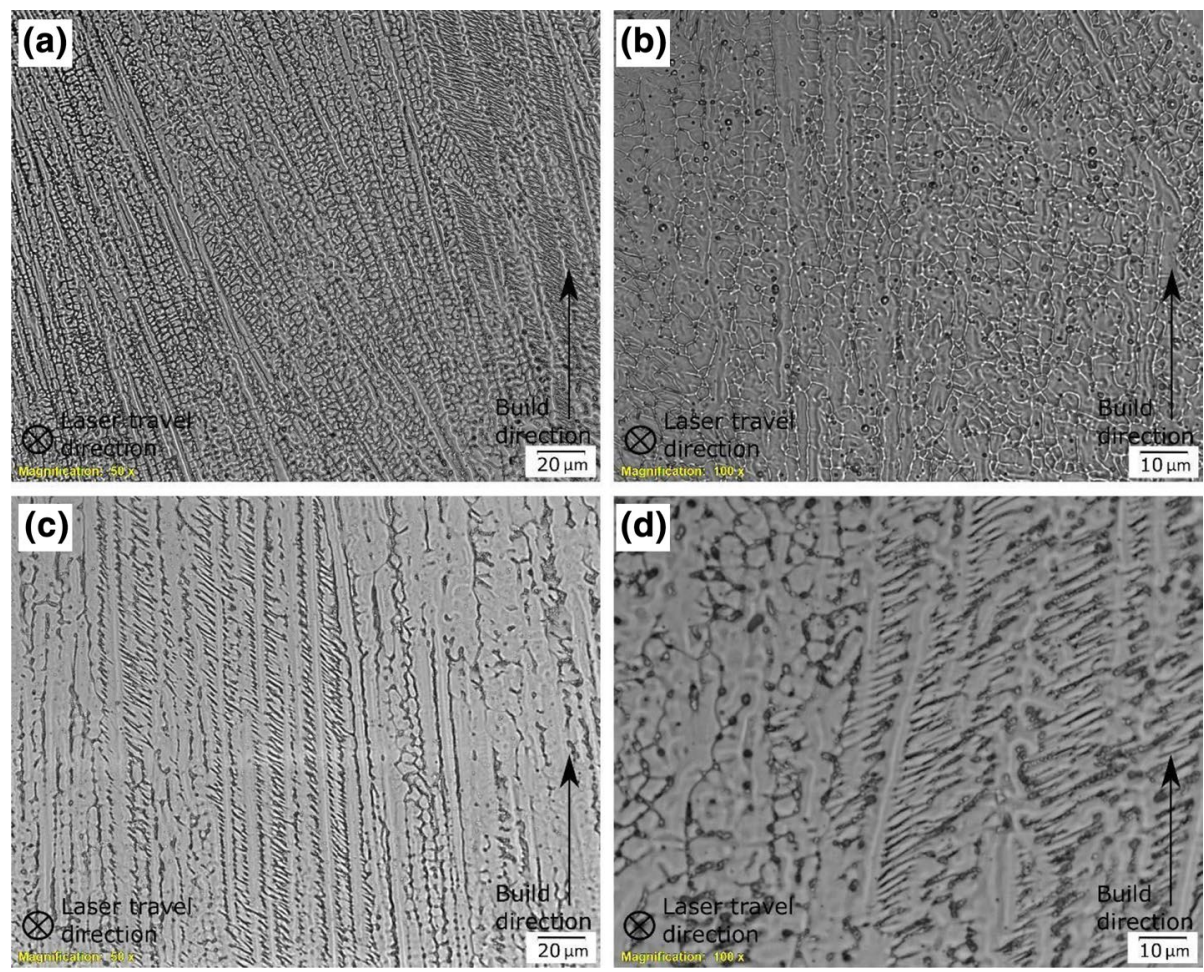

cellular and columnar dendrites. The columnar dendrites in the top layer were solidified perpendicular to the previous layer in the direction of thermal gradient, and it has given a fan-like orientation of the grains.

Further quantitative and qualitative information on the microstructure of the DLD SS316L-Si has also been obtained using EBSD analysis. Figure 9a shows the orientation map for a region above the base material corresponding to specimens prepared from sample CS. The figure exhibits large columnar grains that are nearly orientated along the building direction as confirmed with SEM and LOM. The length of the grain in the elongated direction is about 5-10 times larger than the width of the grain. The length and width of the columnar grains shown in Fig. 9 is about $430 \mu \mathrm{m}$ and $50 \mu \mathrm{m}$, respectively. The grain size distribution of the columnar grains is presented in Fig. 9e. Image quality map corresponding to the image in Fig. 9a is shown in Fig. 9b. Over $70 \%$ of the grain boundaries exhibit a low misorientation angle of about $1^{\circ}-4^{\circ}$ as shown in Fig. 9d. The lower misorientation angles and the variations in the colour within the grains shown in the inverse pole map of Fig. 9a suggest the presence of sub-grains and/or lattice distortions. The sub-grains measure up to $125 \mu \mathrm{m}$ long with an average width of $26 \mu \mathrm{m}$. This result agrees with previous studies $[7,21]$ that show similar observations in microstructure. The pole figure shown in Fig. 9c reveals that the material has a preferential orientation generating solidification texture $<001>$ along build, laser travel and transverse direction. The vertical displacement of the clustered poles is assumed to be attributed to the grains growing with a slight angle in the laser travel direction (towards the reader). The texture observed indicates that the material exhibits some anisotropic mechanical properties [22].

\subsubsection{Secondary phase ( $\delta$-ferrite)}

The analysis with TEM reveals formation of secondary phase of different morphologies. Figure 10 shows a TEM bright-field image of a 1- $\mu \mathrm{m}$ particle with globular shape. The inset in Fig. 10 is one of the selected area electron diffraction (SAED) patterns taken from a tilt series of the particle. The SAED pattern is consistent with a body-centred cubic (bcc) crystal viewed along the [111] zone axis, revealing a ferritic crystal structure. The lattice parameter of the unit cell is about $0.295 \mathrm{~nm}$. It is a bit larger than the values reported in the literature. For example, Liu [23] measured a lattice parameter, $a=0.287 \mathrm{~nm}$, for a bcc lattice structure of $\delta$-ferrite. Such differences in the lattice parameters can be associated with the variations in the nominal compositions. The difference can also occur due to measurement related errors.

The $\delta$-ferrite phase may appear in three different types of morphology-globular specks, lathy and vermicular. The latter has a softer and smoother appearance, while the lathy appears as a needle-shaped particle. Our observation shows that the $\delta$-ferrite with globular morphology prevails closer to the base material, and they are mainly 
Fig.9 Quantitative data from EBSD orientation mapping of sample CS suggesting the presence of sub-grains, texture and grain boundary misorientation. a Inverse pole figure orientation map, b image quality map showing grain structures and $\mathbf{c}(001)$ pole figure, where $B D, T D$ and LTD refer to building direction, transverse direction and laser travel direction, respectively. $\mathbf{d}$ shows the misorientation angle, while $\mathbf{e}$ is the grain size distribution of the columnar grains
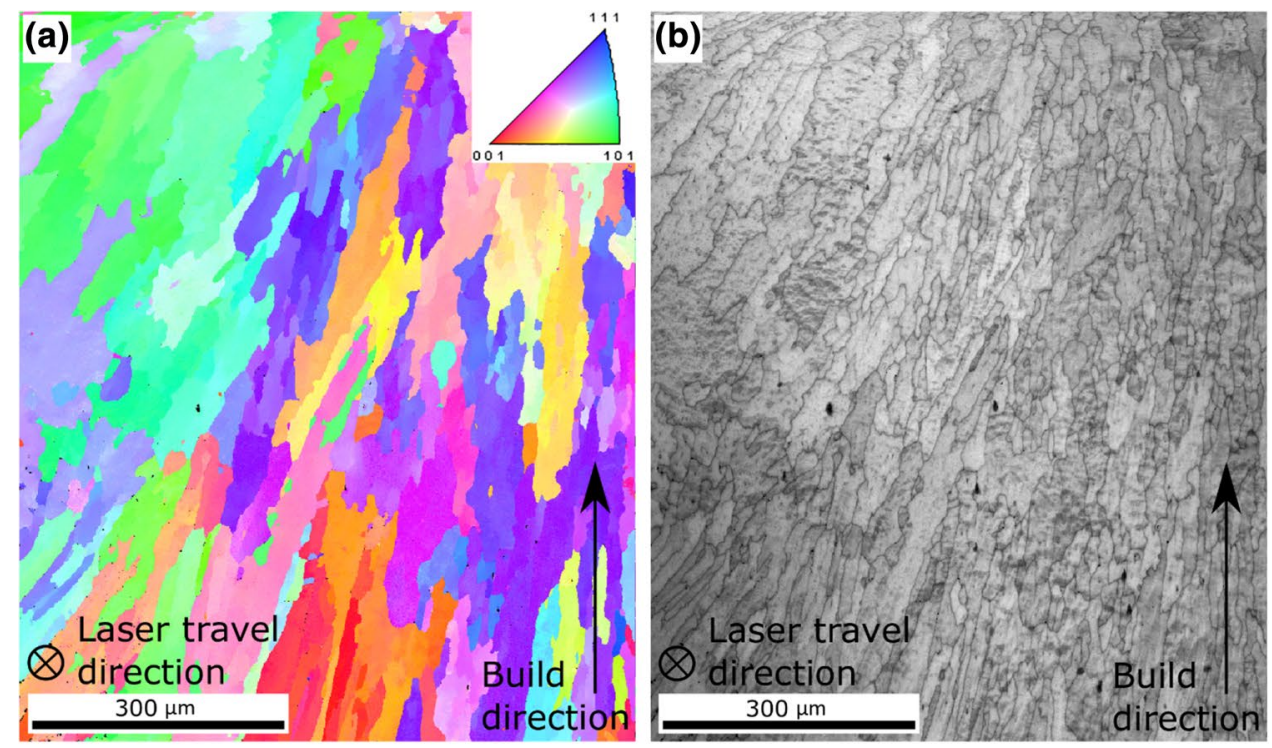

(c)

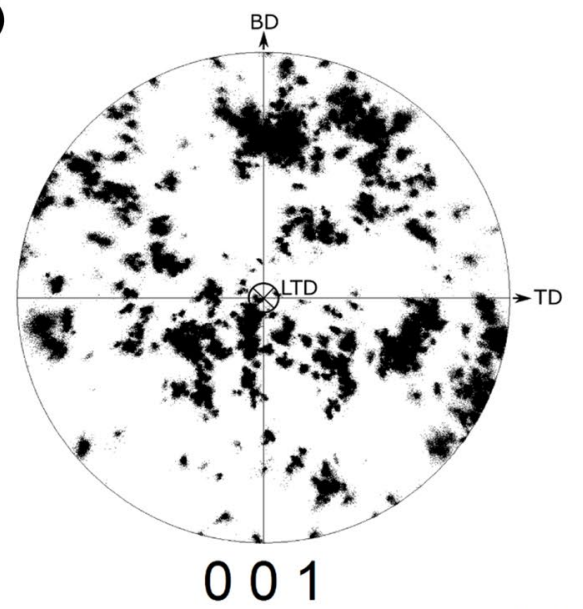

(d)

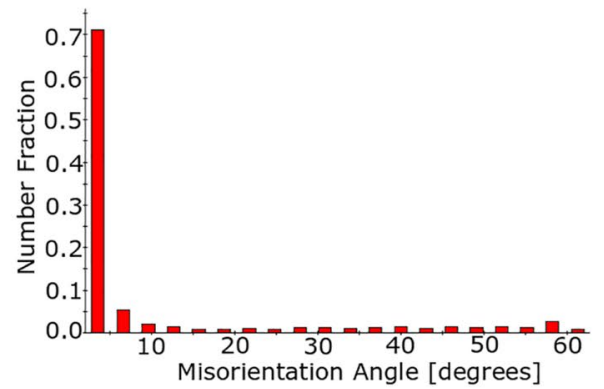

(e)

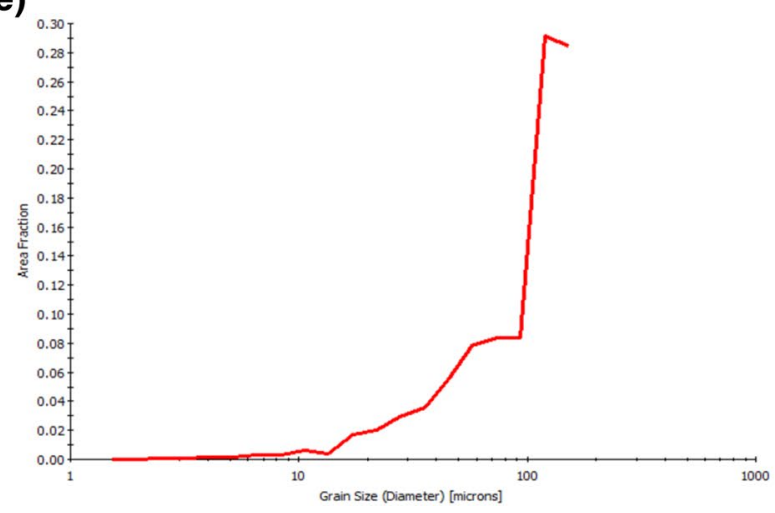

formed along the dendritic boundaries. The globular morphology is favoured by the repeated thermal cycling of the deposited material. It is believed that the repeated heat input breaks the initial vermicular and lathy structures and transforms it into smaller globular specks of $\delta$-ferrite. The morphology transformation is thus the result of shape instabilities of lathy particles and the formation of the thin $\delta$-ferrite when exposed to high cyclic temperatures as pointed out by David and co-workers [24]. Further away from the base material, the $\delta$-ferrite is identified initially as lathy and vermicular morphology due to less cyclic temperature variation.

EBSD was utilized to quantify the phases present in the deposited SS316L-Si. Figure 11 shows an EBSD phase map 


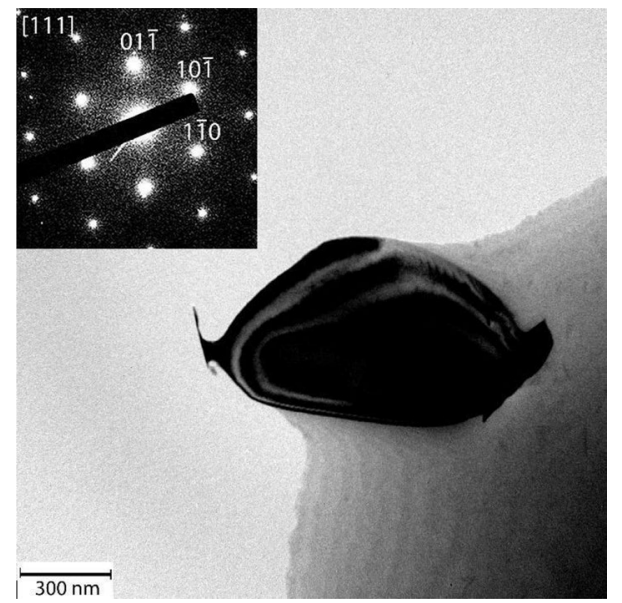

Fig. 10 TEM bright-field image showing secondary $\delta$-ferrite of globular morphology precipitated in DLD SS316L-Si. The inset is a SAED pattern of the particle in the [111] projection

of the deposited SS316L-Si specimen. It reveals the presence of the austenitic phase and a smaller fraction of the secondary $\delta$-ferrite. The latter appears as vermicular and globular morphology, which is formed mainly in the intergranular regions. Quantitative analysis of the phase map reveals a volume fraction of $2.5 \%$ ferrite. It is worthwhile to compare the amount of ferrite concentration obtained experimentally with the theoretical values. The concentration of ferrite present in the austenite matrix can be estimated using the well-known Schaeffler diagram [25]. The main axes of the diagram correspond to $\mathrm{Cr}$ equivalent and $\mathrm{Ni}$ equivalent. The $\mathrm{Cr}$ equivalent is predicted from the weight percentage of ferrite stabilizing elements using Eq. (2). Similarly, the Ni equivalent is calculated using the weight percentage of austenite stabilizing elements given in Eq. (3). Based on the Schaeffler's diagram, the feedstock of the DLD-deposited SS316L-Si contains a volume fraction up to $5 \% \delta$-ferrite at room temperature. This value is twice as much as the experimental result obtained from the EBSD map. The difference may be related to poor statistics of the quantitative analysis.

$\mathrm{Cr}$ equivalent $=\mathrm{Cr}+\mathrm{Mo}+1.5 \mathrm{Si}+0.5 \mathrm{Nb}$

$\mathrm{Ni}$ equivalent $=\mathrm{Ni}+0.5 \mathrm{Mn}+30 \mathrm{~N}+30 \mathrm{C}$

Figure 12a shows vermicular and some globular type $\delta$-ferrite. Composition analysis with EDS on the structures indicated by arrows in Fig. 12a confirms the formation of $\delta$-ferrite phase. The elemental composition obtained from locations 1 and 2 is given in Table 3. The composition of the austenite matrix analysed from location 2 is comparable with the composition of the powder material. However, the composition of location 1 as listed in Table 3 is enriched in chromium, molybdenum and silicon. These elements are strong ferrite stabilizers that promote the formation of $\delta$-ferrite in the printed SS316L-Si [2]. Figure 12b shows a lathy type $\delta$-ferrite structure in the interdendritic region surrounded by austenite. Figure $12 \mathrm{c}$ shows a line scan close to a fusion boundary that contains multiple dendrites with a continuous network of vermicular and globular $\delta$-ferrite in the interdendritic and sub-grain boundary region. In the interdendritic regions, $\mathrm{Ni}$ and $\mathrm{Fe}$ concentrations dropped, while the concentrations of $\mathrm{Cr}$, $\mathrm{Si}$ and Mo increased as shown from the EDS line scan analysis, confirming the result with the EBSD phase map. The formation of $\delta$-ferrite generally reduces the concentration of $\mathrm{Cr}$ and Mo from the $\mathrm{y}$-matrix.

As the initial austenitic dendrites grow, segregation of some of the heavier elements occurs. The remaining melt in the interdendritic regions will thus have some elemental fluctuations. As the austenitic dendrites continue growing, some of the remaining melt will attain higher concentrations of ferrite stabilizing elements. This enhances the formation of $\delta$-ferrite in the cellular and
Fig. 11 High-magnification EBSD image of sample PS: a phase map and $\mathbf{b}$ the image quality map showing intergranular boundaries
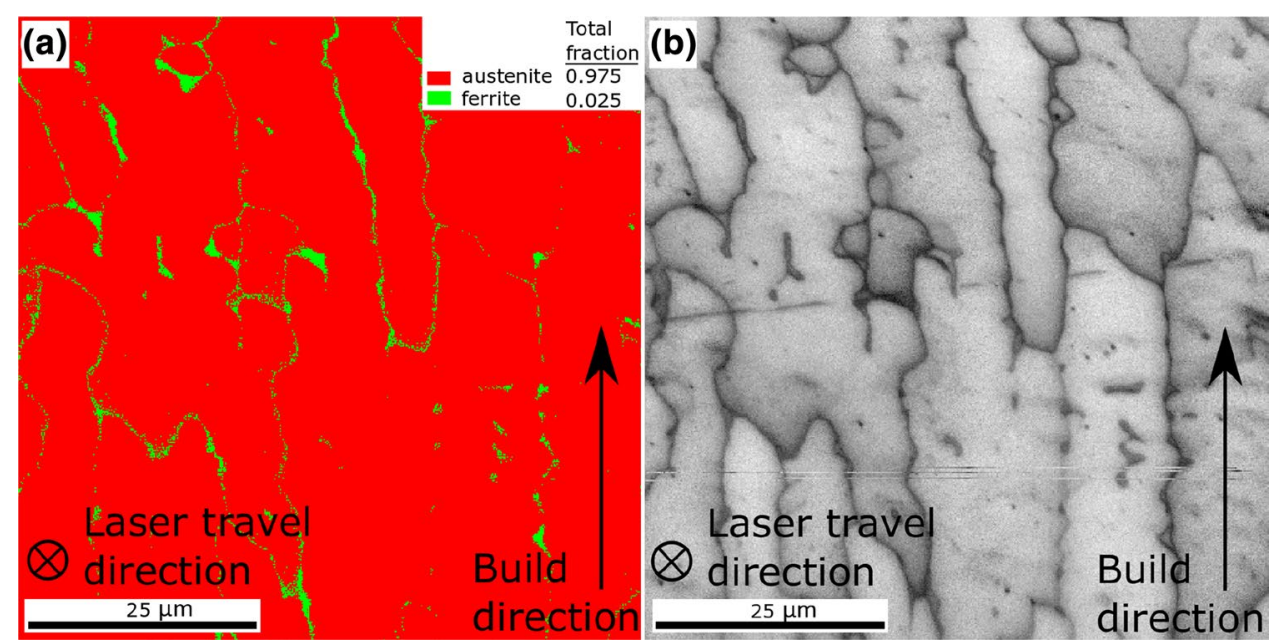
Fig. $12 \delta$-ferrite in the deposited material. a SEM image showing vermicular and globular morphologies of the $\delta$-ferrite in the microstructures of sample CS. The arrows indicate some of the $\delta$-ferrite structures. The numbers 1 and 2 are the approximate location of the composition listed in Table 3. b TEM image showing $\delta$-ferrite with lathy morphology in sample PS in the interdendritic region of the austenite. c EDS line scan in the region of fusion line between two layers, showing variations of composition between the $\delta$-ferrite structures and the matrix in sample CS
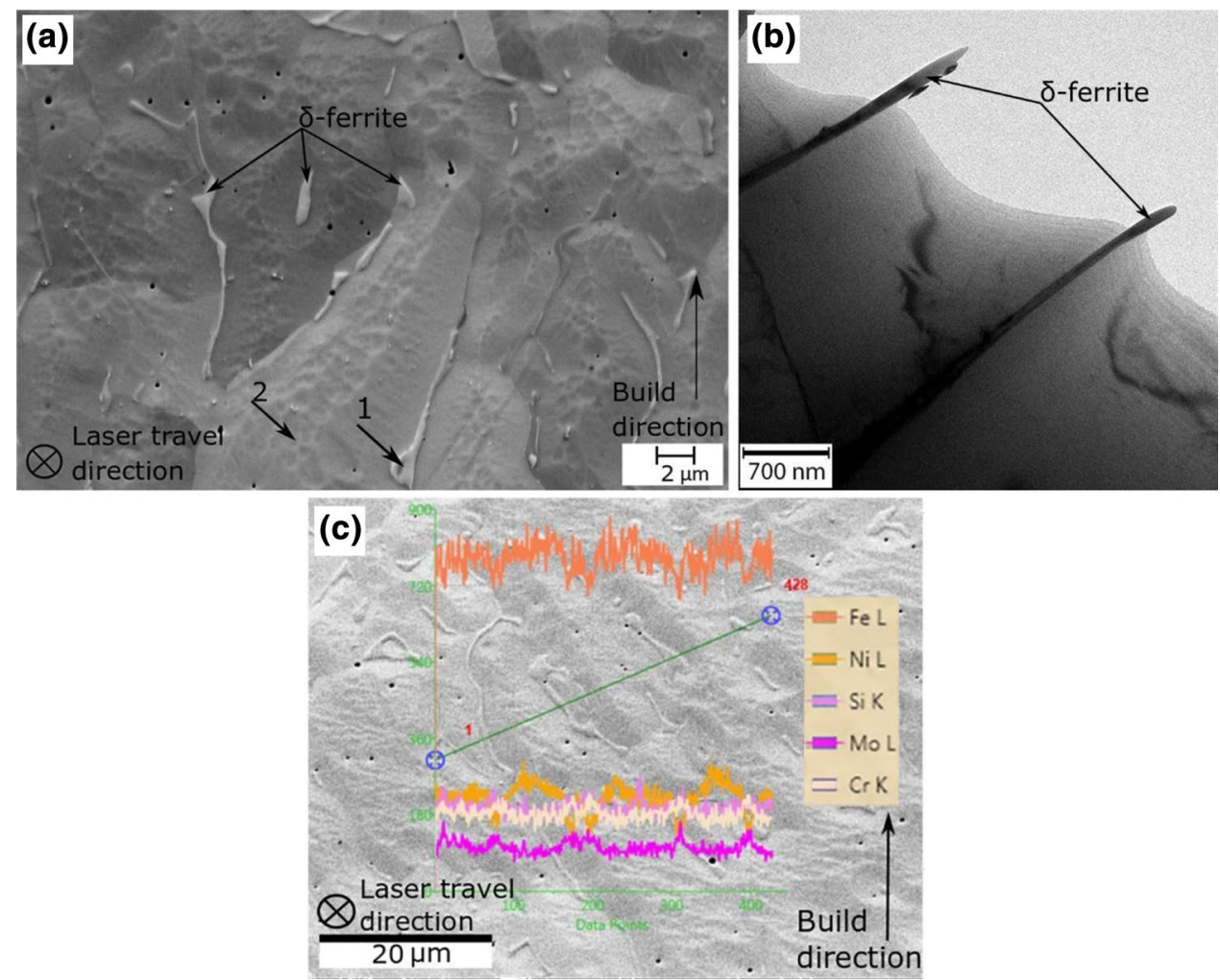

\begin{tabular}{llllllll}
\hline & $\mathrm{C}$ & $\mathrm{Mn}$ & $\mathrm{Si}$ & $\mathrm{Cr}$ & $\mathrm{Ni}$ & $\mathrm{Mo}$ & $\mathrm{Fe}$ \\
\hline 1 (ס-ferrite) & $\mathrm{N} / \mathrm{A}$ & 0.0 & 5.0 & 32.2 & 6.5 & 7.1 & 49.2 \\
2 (austenitic matrix) & $\mathrm{N} / \mathrm{A}$ & 0.4 & 2.1 & 18.0 & 12.5 & 1.7 & 65.1 \\
Powder material & 0.03 & 1.0 & 2.3 & 17.0 & 12.0 & 2.5 & balance \\
\hline
\end{tabular}

Table 3 EDS measured composition [wt\%] of features indicated by arrows in Fig. 12a which has more space to host these elements. Such sites can thus facilitate the formation of undesirable phases/ defects.

\subsection{Defects}

\subsubsection{Segregation of alloying elements}

Some of the segregated elements in the deposited SS316L-Si are shown in Fig. 13. The analyses of the compositions with EDS from the locations labelled in the image are listed in Table 4. The result shows that the concentration of $\mathrm{Mo}, \mathrm{Ni}$ and $\mathrm{Si}$ is decreased, while the concentration of $\mathrm{Cr}$ is increased compared to the nominal composition of the austenite matrix. Previous reports $[3,9]$ have also shown segregation of elements during solidification in the other AM methods, e.g. selective laser melting, and laser engineered net shaping. Similarly, segregation is known to occur during welding of $316 \mathrm{~L}$ stainless steel [30]. Segregation of the alloying elements has a detrimental effect on the physical and mechanical properties of the material. 


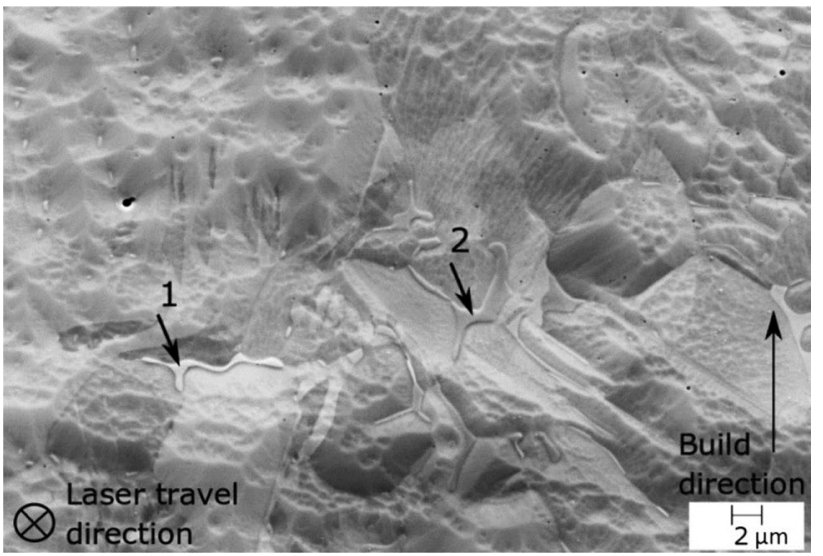

Fig. 13 SEM image showing segregation of alloying elements along the grain boundaries in sample CS

The irregular distribution of $\mathrm{Cr}$ and Mo due to segregation, for instance, weakens the corrosion resistivity of the SS316L-Si.

The mechanisms for segregation of heavier elements in AM-fabricated materials are similar to that of welding since the solidification processes of the two techniques are identical. The explanation given for the segregation in the welding technology by Banovic and co-workers [31], for instance, is helpful to understand the segregation behaviour that occurs during solidification in the DLD. According to Banovic and co-workers, when the heat input increases, the cooling rate will decrease and give rise to increased dendrite size. In addition, the elements in the solute are not distributed evenly. As the weld pool increases, the distance which the elements travel to compensate for the difference also increases. Molybdenum and chromium, which have lower diffusion rates in the face-centred cubic austenite than manganese and nickel, are then forced to segregate into the liquid phase in the gradually solidifying melt pool. As the amount of the solidified solute increases, some of the regions are impoverished, while others are enriched in $\mathrm{Cr}$ and Mo. Hence, as the grains are kept growing, patches enriched in heavier alloying elements (such as $\delta$-ferrite) are formed. The formation of $\delta$-ferrite in SS316L clearly depletes the concentrations of chromium and molybdenum in the $\gamma$ matrix. It is thus important to minimize segregation, by either decreasing heat input or increasing cooling rate during the solidification process.

\subsubsection{Silicate inclusions and dislocations}

Precipitates with spherical morphology with the size as big as $300 \mathrm{~nm}$ are observed in the matrix of the deposited SS316L Si specimens. A typical example of the precipitate is shown in Fig. 14. The precipitates are enriched in $\mathrm{Si}, \mathrm{O}$ and $\mathrm{Al}$, but depleted in $\mathrm{Fe}, \mathrm{Cr}$ and $\mathrm{Ni}$ compared to the corresponding concentrations in the matrix revealed with EDS. Al might be an impurity in the powder material, whereas oxygen could be a residual gas in the building chamber and/or introduced from the oxide layers in the powder material. Since Si has a high chemical affinity for oxygen, it tends to react with the oxygen in the building chamber and form silicate type precipitates. Silicates as precipitates are characterized with spherical morphology due to their high viscous nature in the melted state that promotes surface tension and leads to formation of sharp interfaces. The silicate-based precipitates thus do not dissolve with the steel due to the high surface tension that gives rise to low wettability [9]. Alternatively, these precipitates might have existed before the melting of the powder and readily transferred to the as-deposited part. As shown in the image, the precipitate impedes the movement of dislocations and leads to piling and entanglement of dislocations around the precipitate.

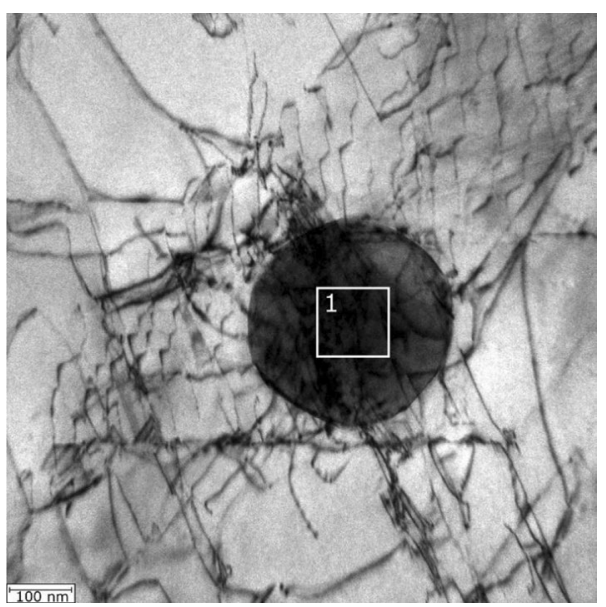

Fig. 14 TEM BF image of precipitate rich in $\mathrm{Si}, \mathrm{O}$ and $\mathrm{Al}$ in the deposited SS316L. The precipitate is surrounded by a high density of dislocation networks. The marked region is analysed for chemical composition with EDS
Table 4 Elemental composition analysed from points 1 and 2 indicated in Fig. 11c)

\begin{tabular}{lllllll}
\hline$\#$ & $\mathrm{Mn}$ & $\mathrm{Si}$ & $\mathrm{Cr}$ & $\mathrm{Ni}$ & $\mathrm{Mo}$ & $\mathrm{Fe}$ \\
\hline 1 [wt\%] & 0.2 & 1.6 & 35.8 & 2.9 & 0.9 & 58.6 \\
2 [wt\%] & 0.0 & 1.6 & 43.4 & 0.9 & 1.1 & 53 \\
Austenitic matrix & 0.4 & 2.1 & 18.0 & 12.5 & 1.7 & 65.1 \\
\hline
\end{tabular}


Dislocations are formed during solidification of the melt pool from the local stresses. Due to differences in coefficient of thermal expansion between the precipitate and the matrix $\left(\sim 5.5 \times 10^{-7}{ }^{\circ} \mathrm{C}^{-1}\right.$ for silicates and $\sim 1.6 \times 10^{-5}{ }^{\circ} \mathrm{C}^{-1}$ for $\mathrm{SS} 316 \mathrm{~L}$ ), tensile stress is generated in the steel matrix in close proximity to the precipitate and subsequently a compressive stress on the silicate [9]. These variations in stress fields in the matrix may give rise to the large concentration of dislocations surrounding the precipitates, thus increasing the hardness and improving the mechanical properties [32]. On the other hand, the silicate precipitates have negative impacts on the material since their presence introduces sites for possible pitting corrosion [33].

Furthermore, TEM investigation reveals dislocations in the proximity of sub-grain boundaries. Typical bright-field TEM images are shown in Fig. 15a, b, revealing dislocations, along the grain boundaries and at the triple junction, respectively. In Fig. 15b, $\delta$-ferrite with globular morphology precipitated at the triple junction is seen entangled by a dense dislocation network. The sub-grains exhibit lowangle boundaries, and have dimensions ranging from a couple of microns to a few tens of microns. The presence of sub-grains in the DLD-SS316L-Si is only revealed based on the colour variations of crystallographic orientation map of grains shown in 9a and the low misorientation angles shown in Fig. 9d. Nevertheless, the larger melt pool and slower cooling rate of DLD compared to other AM techniques (e.g. SLM) prevent formation of intricate dislocation networks observed in previous studies in SS316L [34]. The formation of lower density of dislocations in DLD-SS316L$\mathrm{Si}$, such as the present study, can be associated with the slower solidification rate, relaxation of residual stresses and localized strain due to the continuous reheating during subsequent material deposition [35].

\subsubsection{Pores}

Both spherical and non-spherical pores were observed in the DLD-deposited SS316L-Si part. The pores seen in sample CS are generally spherical and found evenly distributed as shown in Fig. 16a. Figure 16b is taken from sample PS and shows that some of the spherical pores seen in sample $\mathrm{CS}$ can be the cross sections of the non-spherical pores.

The formation of pores and layered voids can be due to the effects of process parameters including thermal coefficient of the base material, porosity in the precursor powder [7] and trapped gas. As the argon gas used to create an inert environment in the building chamber is non-soluble in steels, it can be trapped in the melt pool during deposition and generate spherical pores [36]. Analysis of the spherical pore concentrations on the surfaces of sample CS with ImageJ shows a material density of about $99.5 \%$. As expected, this value is slightly less than the material density of the SLM-fabricated SS316L. Tucho and his coworkers [15], for example, measured a material density of about $99.8 \%$ for SLM-SS316L and suggested further optimization by tuning the process parameters.

The analysis of the plane-view (parallel to the laser scanning plane) specimen (sample PS) reveals layered voids, as shown in Fig. 16b. These types of voids are, however, not seen in the cross-sectional specimen (sample CS). Similar inter-track pores have also been reported previously [37] on cladded-fabricated material that used feedstock powder in the range of $40-140 \mu \mathrm{m}$. These types of pores are usually formed if the laser energy input is insufficient to melt all the powdered material introduced in the melt pools. To avoid or minimize the porosity, the overlap between each deposited layer should be at least $50 \%$ as shown by Yu et al. [38], based on laser deposition technique using a fractal pattern.
Fig. 15 Bright-field TEM image of sample PS showing: a dislocations in the sub-grains and b a triple junction with a speck of globular $\delta$-ferrite entangled with dislocations
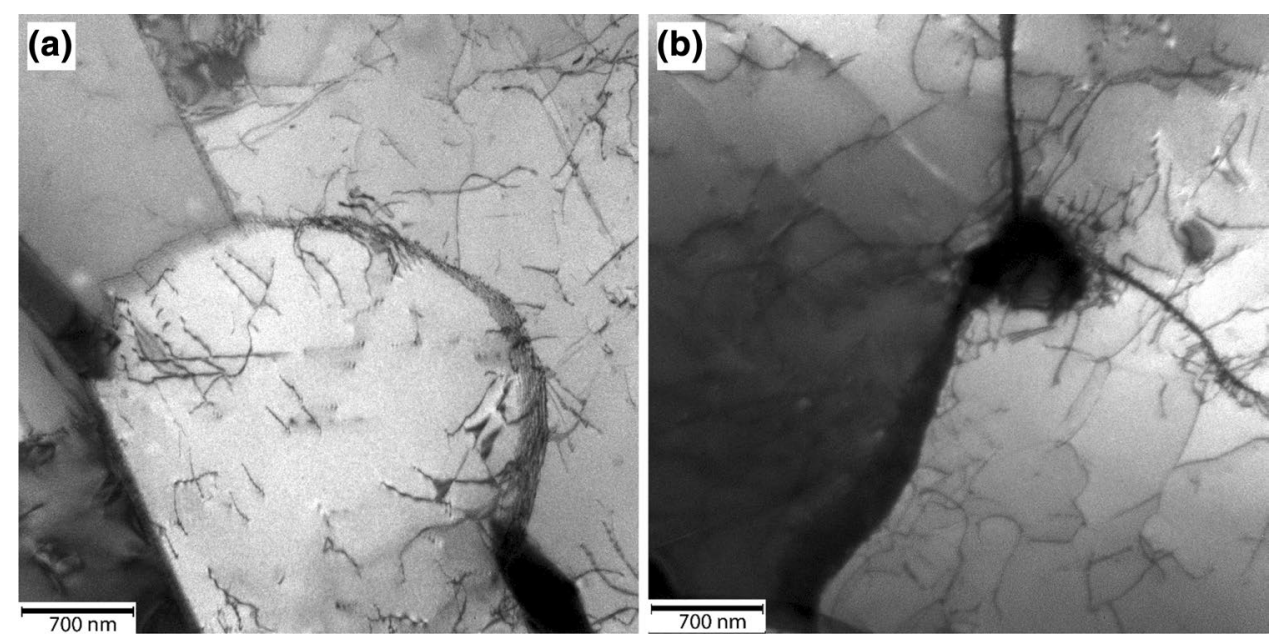
Fig. 16 Porosity in SS316L-Si a spherical pores in sample CS (cross-sectional view) and $\mathbf{b}$ inter-track porosity observed in sample PS (parallel to the laser scanning plane)

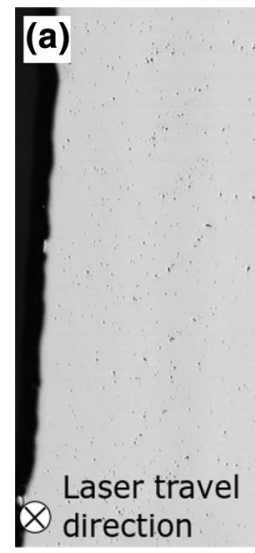

\subsection{Hardness measurement}

In order to investigate heterogeneity of the microstructure of the deposited material, hardness measurements were taken on the two surfaces/samples-normal and parallel to the build direction. The average hardness measured for both surfaces is nearly the same. These are $186 \pm 4 \mathrm{HV}$ for sample CS and $184 \pm 4 \mathrm{HV}$ for sample PS. The similarities of the hardness values of the two orthogonal surfaces suggest homogeneity of the microstructure in the two directions.

Compared to the average hardness of the conventional SS316L (155 HV) [39], the hardness of the DLD SS316L-Si is larger by at least $19 \%$. The higher hardness for the deposited material is assumed to be attributed to the concentration of the $\delta$-ferrite, dislocations and the segregated alloying elements. These defects in the grains and along the grain boundaries act like roadblocks, repressing dislocation movement and generating dislocation pile-ups during plastic deformation. Hence, their existence leads to the need of increased force to achieve deformation. Regardless of the complexity, the lack of severe dislocation networks and the homogeneous distribution of $\delta$-ferrite lead to a more coherent resistance to plastic deformation than with other printing techniques [2].

The hardness values are consistent with the results in the previous studies for direct-laser-deposited 316 Ltainless steel [40] and comparable with EBM-SS316L [41]. On the other hand, the hardness of DLD SS316L is inferior compared to that of SLM and LENS-fabricated SS316L. Tucho et al. [11] reported hardness values as high as 213 $\pm 3 \mathrm{HV}$ in the plane normal to build direction and $188 \pm$ $4 \mathrm{HV}$ parallel to the laser travel direction. Ziętala et al. [2] obtained an average microhardness value of $289 \pm 16 \mathrm{HV}$ perpendicular to the layers in the part and slightly lower average of $272 \pm 35 \mathrm{HV}$ parallel to the layers. These materials generally exhibit heterogeneity in the microstructure that might be attributed to the nature of the defects formed.

The big variation in hardness between the DLD and other AM-fabricated SS316L is due to the difference in microstructure associated with respective techniques. The large, solidified melt pools observed from the DLD process accommodate larger grain structures than the other techniques, in particular SLM and LENS. The two latter methods generate smaller melt pools of about $100 \mu \mathrm{m}$ compared to DLD, which form melt pools in the $\mathrm{mm}$ range. The structure in SLM-processed material consists of sub grains [11] with boundaries rich in dislocation networks which leads to a higher hardness than that of the DLD produced material.

\section{Conclusions}

- The current study investigates the microstructure and hardness of deposited SS316L-Si on a conventional SS316L base material using the DLD method.

- The study shows that the DLD process can produce a defect-free fusion zone with a solid metallurgical bond between the two materials, displayed by the epitaxial nucleation of the columnar grains in the deposited material.

- The deposited SS316L-Si exhibits a duplex microstructure containing primary austenite and secondary $\delta$-ferrite phases. EBSD analysis shows a volume fraction of about $2.5 \% \delta$-ferrite in the interdendritic and subgrain boundaries.

- The increased hardness of the deposited SS316L-Si was due to the pinning of dislocations by the $\delta$-ferrite and segregated alloying elements in the interdendritic regions.

- The study reveals formation of a few inter-track porosities in the laser travel direction together with segregated alloying elements which occurred during solidifi- 
cation. Based on quantification of porosity, the material density of the DLD-deposited SS316L-Si is about $99.5 \%$. The density can be further improved by tuning the process parameters of DLD.

Acknowledgements The authors would like to thank Geir Tandberg (TechnipFMC Subsea) for supplying the material used for this study.

Funding This research did not receive any specific grant from funding agencies in the public, commercial or not-for-profit sectors.

Availability of data and material The processed data required to reproduce these findings are available to download from https:// drive.google.com/open?id=1 np4UkLJQuT1IU2EdDO2OBXi3jqLOD T3Q

\section{Compliance with ethical standard}

Conflicts of interest There is not any conflict of interest from the authors that could influence the submitted work.

\section{References}

1. Kruth JP, Leu MC, Nakagawa T (1998) Progress in additive manufacturing and rapid prototyping. CIRP Ann 47:525-540

2. Ziętala M, Durejko T, Polański M, Kunce I, Płociński T, Zieliński W, Łazińska M, Stępniowski W, Czujko T, Kurzydłowski KJ, Bojar Z (2016) The microstructure, mechanical properties and corrosion resistance of $316 \mathrm{~L}$ stainless steel fabricated using laser engineered net shaping. Maters Sci Eng A 677:1-10

3. Zhang K, Liu W, Shang X (2007) Research on the processing experiments of laser metal deposition shaping. Opt Laser Technol 39:549-557

4. Yang G, Lin X, Liu F, Hu Q, Ma L, Li J, Huang W (2012) Laser solid forming Zr-based bulk metallic glass. Intermetallics 22:110-115

5. Thompson SM, Bian L, Shamsaei N, Yadollahi A (2015) An overview of Direct Laser Deposition for additive manufacturing. Part I: Transport phenomena, modeling and diagnostics, Additive Manufacturing 8:36-62

6. Kalinin G, Barabash V, Cardella A, Dietz J, loki K, Matera R, Santoro RT, Tivey R (2000) Assessment and selection of materials for ITER in-vessel components. J Nucl Mater 283-287:10-19

7. Yadollahi A, Shamsaei N, Thompson SM, Seely DW (2015) Effects of process time interval and heat treatment on the mechanical and microstructural properties of direct laser deposited $316 \mathrm{~L}$ stainless steel. Mater Sci Eng, A 644:171-183

8. Majumdar JD, Pinkerton A, Liu Z, Manna I, Li L (2005) Microstructure characterisation and process optimization of laser assisted rapid fabrication of $316 \mathrm{~L}$ stainless steel. Appl Surf Sci 247:320-327

9. Saeidi K, Gao X, Zhong Y, Shen ZJ (2015) Hardened austenite steel with columnar sub-grain structure formed by laser melting. Mater Sci Eng, A 625:221-229

10. Lewis GK, Schlienger E (2000) Practical considerations and capabilities for laser assisted direct metal deposition. Mater Design 21:417-423

11. Tucho WM, Lysne VH, Austbø $H$, Sjolyst-Kverneland A, Hansen $V$ (2018) Investigation of effects of process parameters on microstructure and hardness of SLM manufactured SS316L. J Alloys Compounds 740:910-925

SN Applied Sciences
12. Metco O (2014) Material Product Data Sheet Austenitic Stainless Steel Powder for Laser Cladding, in, Oerlikon Metco. https ://www.oerlikon.com/ecomaXL/files/metco/oerlikon_DSM0269.0_316L_Austenitic_SS.pdf\&download=1

13. A. International, ASTM E3-11(2017), Standard Guide for Preparation of Metallographic Specimens, in, ASTM, 2017

14. Chen XH, Lu J, Lu L, Lu K (2005) Tensile properties of a nanocrystalline $316 \mathrm{~L}$ austenitic stainless steel. Scripta Mater 52:1039-1044

15. Elmer JW, Allen SM, Eagar TW (1989) Microstructural development during solidification of stainless steel alloys. Metall Trans A 20:2117-2131

16. Mazumder J (2017) 1-Laser-aided direct metal deposition of metals and alloys A2. In: Brandt M (ed) Laser Additive Manufacturing, Woodhead Publishing, pp 21-53

17. Rosa DM, Spinelli JE, Ferreira IL, Garcia A (2008) Cellular/Dendritic transition and microstructure evolution during transient directional solidification of $\mathrm{Pb}-\mathrm{Sb}$ alloys. Metall Mater Trans $\mathrm{A}$ 39:2161-2174

18. Gäumann M, Henry S, Cléton F, Wagnière JD, Kurz W (1999) Epitaxial laser metal forming: analysis of microstructure formation. Mater Sci Eng, A 271:232-241

19. Zhang K, Wang S, Liu W, Shang X (2014) Characterization of stainless steel parts by Laser Metal Deposition Shaping. Mater \& Design 55:104-119

20. Grong $\varnothing$ (1994) Metallurgical modelling of welding. Institute of Materials, London

21. Zhang Y, Yang L, Dai J, Huang Z, Meng T (2016) Grain growth of $\mathrm{Ni}$-based superalloy IN718 coating fabricated by pulsed laser deposition. Opt Laser Technol 80:220-226

22. Niendorf T, Leuders S, Riemer A, Richard HA, Tröster T, Schwarze D (2013) Highly anisotropic steel processed by selective laser melting. Metall Mater Trans B 44:794-796

23. Liu P, Sandvik T (2004) Materials, phase analysis in steel using analytical transmission electron microscopy, Sandvik Materials Technology, Sandviken, pp 123-136

24. S.A. David, S.E. Hanzelka, C.P. Haltom, Ferrite morphology and variations in ferrite content in austenitic stainless steel welds, in,; Oak Ridge National Lab., TN (USA), 1981, pp. Medium: X; Size: Pages: 36

25. Sandvik, Ferrite content diagrams - Schaeffler diagram, in, 2018, pp 353, Schaeffler diagram. https://www.meting.rs/wp-content/ uploads/2018/05/welding-handbook.pdf

26. Takalo T, Suutala N, Moisio T (1979) Austenitic solidification mode in austenitic stainless steel welds. Metall Trans A 10:1173-1181

27. Lippold JC, Savage WF (1979) Solidification of austenitic stainless steel weldments: part 1-A proposed mechanism. Weld J 58:362-374

28. Mozhi TA, Clark WAT, Wilde BE (1987) The effect of nitrogen and carbon on the stress corrosion cracking performance of sensitized AISI 304 stainless steel in chloride and sulfate solutions at $250^{\circ} \mathrm{C}$. Corros Sci 27:257-273

29. Kumar DH, Reddy AS (2013) Study of mechanical behavior in austenitic stainless steel 316 LN welded joints. Int J Mech Eng Robot Res 2:37-56

30. Kourdani A, Derakhshandeh-Haghighi R (2018) Evaluating the properties of dissimilar metal welding between Inconel 625 and $316 \mathrm{~L}$ stainless steel by applying different welding methods and consumables. Metall Mater Trans A 49:1231-1243

31. Banovic SW, Dupont JN, Marder AR (2002) Dilution and microsegregation in dissimilar metal welds between super austenitic stainless steel and nickel base alloys. Sci Technol Weld Join 7:374-383 
32. Eo DR, Park SH, Cho JW Inclusion evolution in additive manufactured 316L stainless steel by laser metal deposition process. Mater Design

33. Ganesh P, Giri R, Kaul R, Ram Sankar P, Tiwari P, Atulkar A, Porwal RK, Dayal RK, Kukreja LM (2012) Studies on pitting corrosion and sensitization in laser rapid manufactured specimens of type stainless steel. Mater Design 39:509-521

34. Liu L, Ding Q, Zhong Y, Zou J, Wu J, Chiu YL, Li J, Zhang Z, Yu Q, Shen Z (2017) Dislocation network in additive manufactured steel breaks strength-ductility trade-off, Materials Today

35. Qiu C, Kindi MA, Aladawi AS, Hatmi IA (2018) A comprehensive study on microstructure and tensile behaviour of a selectively laser melted stainless steel. Sci Rep 8:7785

36. Röttger A, Geenen K, Windmann M, Binner F, Theisen W (2016) Comparison of microstructure and mechanical properties of $316 \mathrm{~L}$ austenitic steel processed by selective laser melting with hot-isostatic pressed and cast material. Mater Sci Eng, A 678:365-376

37. Sun S, Brandt M, Harris J, Durandet $Y$ (2006) The influence of stellite 6 particle size on the inter-track porosity in multi-track cladding. Surf Coat Technol 201:998-1005
38. Yu J, Lin X, Ma L, Wang J, Fu X, Chen J, Huang W (2011) Influence of laser deposition patterns on part distortion, interior quality and mechanical properties by laser solid forming (LSF). Mater Sci Eng, A 528:1094-1104

39. A.A.S.M. Inc, AISI Type 316 Ltainless Steel, annealed plate. In: 2018, pp. Mechanical properties 316 L

40. Sklyar MO, Turichin GA, Klimova OG, Zotov OG, Topalov IK (2016) Microstructure of $316 \mathrm{~L}$ stainless steel components produced by direct laser deposition. Steel Transl 46:883-887

41. Rännar L-E, Koptyug A, Olsén J, Saeidi K, Shen Z (2017) Hierarchical structures of stainless steel $316 \mathrm{~L}$ manufactured by Electron Beam Melting. Addit Manuf 17:106-112

Publisher's Note Springer Nature remains neutral with regard to jurisdictional claims in published maps and institutional affiliations. 